\title{
Contributions of each isotope in structural material on radiation damage in a hybrid reactor
}

\author{
Mehtap Günay \\ İnönü University, Science and Art Faculty, Physics Department, Malatya, Turkey
}

\begin{abstract}
In this study, the fluids were used in the liquid first-wall, blanket and shield zones of the designed hybrid reactor system. In this study, salt-heavy metal mixtures consisting of $93-85 \% \mathrm{Li}_{20} \mathrm{Sn}_{80}+$ $5 \% \mathrm{SFG}-\mathrm{PuO}_{2}$ and $2-10 \% \mathrm{UO}_{2}, 93-85 \% \mathrm{Li}_{20} \mathrm{Sn}_{80}+5 \% \mathrm{SFG}-\mathrm{PuO}_{2}$ and $2-10 \% \mathrm{NpO}_{2}$, and $93-85 \% \mathrm{Li}_{20} \mathrm{Sn}_{80}$ $+5 \% \mathrm{SFG}-\mathrm{PuO}_{2}$ and $2-10 \% \mathrm{UCO}$ were used as fluids. In this study, the effect on the radiation damage of spent fuel-grade (SFG)- $\mathrm{PuO}_{2}, \mathrm{UO}_{2}, \mathrm{NpO}_{2}$ and $\mathrm{UCO}$ contents was investigated in the structural material of a designed fusion-fission hybrid reactor system. In the designed hybrid reactor system were investigated the effect on the radiation damage of the selected fluid according to each isotopes of structural material in the structural material for 30 full power years (FPYs). Three-dimensional analyses were performed using the most recent MCNPX-2.7.0 Monte Carlo radiation transport code and the ENDF/B-VII.0 nuclear data library.
\end{abstract}

\section{Introduction}

Hybrid reactor system has been developed where fusion and fission occur at the same time. Hybrid reactor has an enormous potential to provide a clean, cheap and unlimited energy source. Important advantage of hybrid reactor system is that it has a subcritical reactor system in which reactor can operate securely [1-6].

A substantial amount of spent fuel grade (SFG) plutonium $(\mathrm{Pu})$ from current nuclear reactors has been stored for future use. The isotopic distribution of spent fuel-grade plutonium is $2.4 \%{ }^{238} \mathrm{Pu}, 58.5 \%{ }^{239} \mathrm{Pu}, 24 \%$ ${ }^{240} \mathrm{Pu}, 11.2 \%{ }^{241} \mathrm{Pu}$, and $3.9 \%{ }^{242} \mathrm{Pu}$ [7]. In this study, $\mathrm{Li}_{20} \mathrm{Sn}_{80}$ molten salt was used, which has low melting temperatures and low vapour pressure, to acquire sufficient tritium breeding. Beryllium $(\mathrm{Be})$ is used as a neutron multiplier [8]. In this study, a Be zone with a thickness of $3 \mathrm{~cm}$ was used between the liquid first-wall and the blanket. In this study, 9Cr2WVTa ferritic steel was chosen as a structural material because it has low activation, which can help to extend the lifetime of the reactor system. The main objective of this study is to investigate the effect of the selected fluid on the radiation damage according to each isotopes of structural material in the structural material for the designed hybrid system.

\section{Method}

\subsection{Numerical calculation and radiation damage}

In Table 1 is shown the radial build of the designed hybrid reactor system. Calculation of all the parameters of the fission and fusion reactors, accelerator-driven systems, and other areas of nuclear technology depend on the cross-section data. The experimental data are limited for neutron-produced reactions in certain energy ranges. The data of the ENDF/B-VII libraries are very important for theoretical calculations [9-13]. This study was performed with neutron wall loadings of $10 \mathrm{MW} / \mathrm{m}^{2}$ and fusion power of $4000 \mathrm{MW}$.

Table 1. The radial build of the hybrid reactor system design

\begin{tabular}{|c|c|c|c|}
\hline \multicolumn{2}{|c|}{ Inboard side } & \multicolumn{2}{|c|}{ Outboard side } \\
\hline Zone & $\mathbf{r}(\mathbf{c m})$ & Zone & $\mathbf{r}(\mathbf{c m})$ \\
\hline SS316LN & 276 & Plasma & 667 \\
\hline Vacuum vessel $^{\mathrm{a}}$ & 278 & SOL & 695 \\
\hline SS316LN & 294 & $\begin{array}{l}\text { Liquid First } \\
\text { Wall }^{\mathrm{d}}\end{array}$ & 697 \\
\hline GAP & 296 & $\mathrm{Be}^{\mathrm{e}}$ & 700 \\
\hline Shield $^{\mathrm{b}}$ & 301 & Blanket $^{\mathrm{d}}$ & 750 \\
\hline Ferritic Steel $^{\mathrm{c}}$ & 350 & Ferritic Steel $^{\mathrm{c}}$ & 754 \\
\hline Blanket $^{\mathrm{d}}$ & 354 & Shield $^{\mathrm{b}}$ & 804 \\
\hline $\mathrm{Be}^{\mathrm{e}}$ & 404 & GAP & 838 \\
\hline $\begin{array}{c}\text { Liquid First } \\
\text { Wall }^{\text {d }}\end{array}$ & 407 & SS316LN & 840 \\
\hline SOL & 409 & Vacuum vessel $^{\mathrm{a}}$ & 866 \\
\hline Plasma & 437 & SS316LN & 868 \\
\hline
\end{tabular}

a $80 \%$ SS316LN, $20 \% \mathrm{H}_{2} \mathrm{O}$

b $60 \% 9 \mathrm{Cr} 2 \mathrm{WVTa}, 40 \%\left(93-85 \% \quad \mathrm{Li}_{20} \mathrm{Sn}_{80}+5 \% \quad \mathrm{SFG}-\mathrm{PuO}_{2}\right.$ and $2-10 \% \mathrm{UO}_{2}, 93-85 \% \mathrm{Li}_{20} \mathrm{Sn}_{80}+5 \% \mathrm{SFG}-\mathrm{PuO}_{2}$ and $2-10 \% \mathrm{NpO}_{2}$, and $93-85 \% \mathrm{Li}_{20} \mathrm{Sn}_{80}+5 \% \mathrm{SFG}_{-} \mathrm{PuO}_{2}$ and $2-10 \%$ UCO)

c $100 \%$ 9Cr2WVTa

d $93-85 \% \mathrm{Li}_{20} \mathrm{Sn}_{80}+5 \% \mathrm{SFG}-\mathrm{PuO}_{2}$ and $2-10 \% \mathrm{UO}_{2}$,

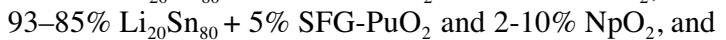
$93-85 \% \mathrm{Li}_{20} \mathrm{Sn}_{80}+5 \% \mathrm{SFG}^{-\mathrm{PuO}}{ }_{2}$ and $2-10 \% \mathrm{UCO}$ $100 \% \mathrm{Be}$ 
Structural materials are exposed to high neutron flux, $\gamma$-rays, and energetic particles that continuously eject atoms from their lattice sites. This leads to various types of damage in the material due to neutron attenuation such as hardening, swelling and embrittlement, which directly influence its function. The abilities to reduce the activation and radiation damage to structural materials are among the most important advantages of liquid walls, particularly the "thick" liquid wall concept in the fusion reactor. Radiation effects are the consequence of radiation damage on the mechanical and physical properties of the solid. Whereas the hydrogen atom and its isotopes produced by (n, p), $(n, d)$, and $(n, t)$ reactions can diffuse out of the first wall material with high temperatures, the helium atoms produced by $(n, \alpha)$ and $(n, H e-3)$ reactions will accumulate in the first wall of the hybrid reactor and produce helium gas bubbles. These reactions will limit the operational lifetime of the structural material of the reactor [14-17].

\section{Numerical Results}

In this study, the fluids were composed of molten salt 93-85\% $\mathrm{Li}_{20} \mathrm{Sn}_{80}+5 \%$ SFG-PuO 2 as the main constituent with increasing mole fractions in $2-10 \%$ rates of the heavy metals $\mathrm{UO}_{2}, \mathrm{NpO}_{2}$, and $\mathrm{UCO}$. The effect of $\mathrm{UO}_{2}$, $\mathrm{NpO}_{2}$, UCO on the radiation damage parameters were investigated according to each isotopes of structural material.

Fig. 1 and Fig. 2 shows comes from Fe isotope of the biggest contribution and from $\mathrm{C}$ isotope of the smallest contribution at the total proton and deuterium production rate, respectively, in the structural material for used fluids. In Fig. 1, contribution at the total proton production rate in the structural material of Fe isotope for used fluids was obtained about $5 \times 10^{5}, 1 \times 10^{3}, 10$, $7 \times 10^{2}, 5 \times 10^{4}, 4 \times 10^{3}$ times higher than $\mathrm{C}, \mathrm{V}, \mathrm{Cr}, \mathrm{Mn}-55$, Ta-181, W isotopes, respectively. In Fig. 2, contribution at the total deuterium production rate in the structural material of $\mathrm{Fe}$ isotope for used fluids was obtained about $1 \times 10^{4}, 3 \times 10^{2}, 2 \times 10^{2}, 2 \times 10^{2}$ times higher than $\mathrm{C}, \mathrm{V}, \mathrm{Cr}$, Mn-55 isotopes, respectively. In Fig. 1 and Fig. 2, the contributions to the total proton and deuterium production rate of $\mathrm{Fe}$ isotope in the structural material was found as approximately $93 \%$ and $99 \%$, respectively.

Fig. 3 shows comes from $\mathrm{Cr}$ isotope of the biggest contribution and from $\mathrm{V}$ isotope of the smallest contribution at the total tritium production rate in the structural material for used fluids. In Fig. 3, contribution at the total tritium production rate in the structural material of $\mathrm{Cr}$ isotope for used fluids was obtained about $1 \times 10^{2}, 20$ and 4 times higher than V, Mn-55 and Fe isotopes, respectively. In Fig. 3, the contributions to the total tritium production rate of $\mathrm{Cr}$ isotope in the structural material was found as approximately $77 \%$.

Fig. 4 shows comes from Fe isotope of the biggest contribution and from $\mathrm{V}$ isotope of the smallest contribution at the total He-3 production rate in the structural material for used fluids. In Fig. 4, contribution at the total He-3 production rate in the structural material of Fe isotope for used fluids was obtained about $2 \times 10^{5}, 6$ and 10 times higher than $\mathrm{V}, \mathrm{Cr}$ and $\mathrm{Mn}-55$ isotopes, respectively. In Fig. 4, the contributions to the total He-3 production rate of $\mathrm{Fe}$ isotope in the structural material was found as approximately $79 \%$.

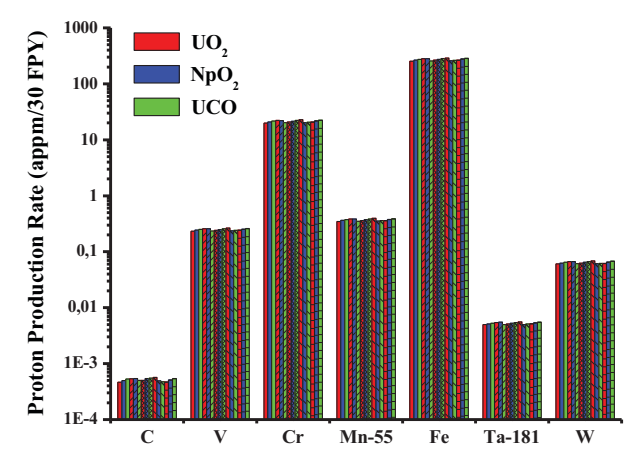

Fig. 1. The contribution of each isotope in the structural material to the total proton production rate for the mixture components of $\mathrm{UO}_{2}, \mathrm{NpO}_{2}$ and $\mathrm{UCO}(\square 2 \%, \mathbb{Z Z / Z} 4 \%$, $6 \%, \triangle \backslash 7 \%$,

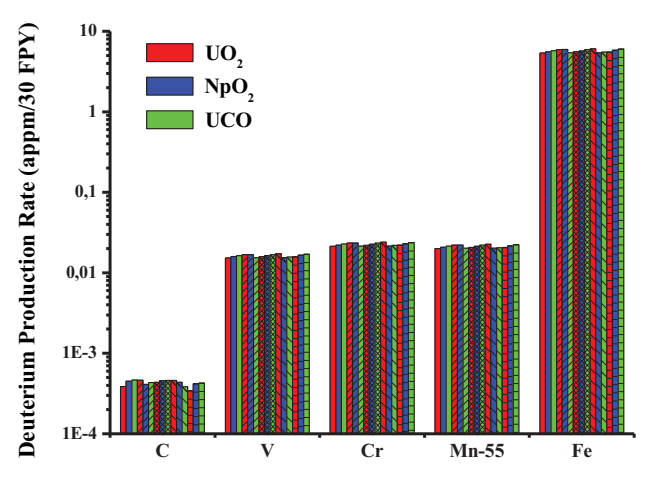

Fig. 2. The contribution of each isotope in the structural material to the total deuterium production rate for the mixture components of $\mathrm{UO}_{2}, \mathrm{NpO}_{2}$ and $\mathrm{UCO}(\square 2 \%, \mathbb{Z Z Z} 4 \%$, $=6 \%, \mathrm{~S} 8 \%$,

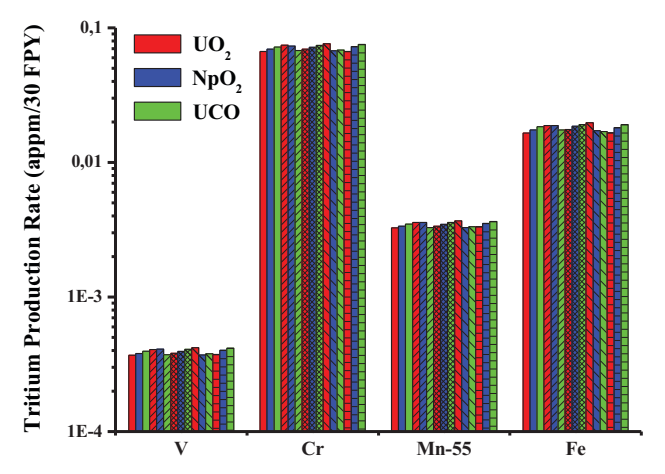

Fig. 3. The contribution of each isotope in the structural material to the total tritium production rate for the mixture components of $\mathrm{UO}_{2}, \mathrm{NpO}_{2}$ and $\mathrm{UCO}(\square 2 \%, \mathbb{Z Z Z} 4 \%$, \% $6 \%$, $8 \%$, $10 \%)$ in the system. 


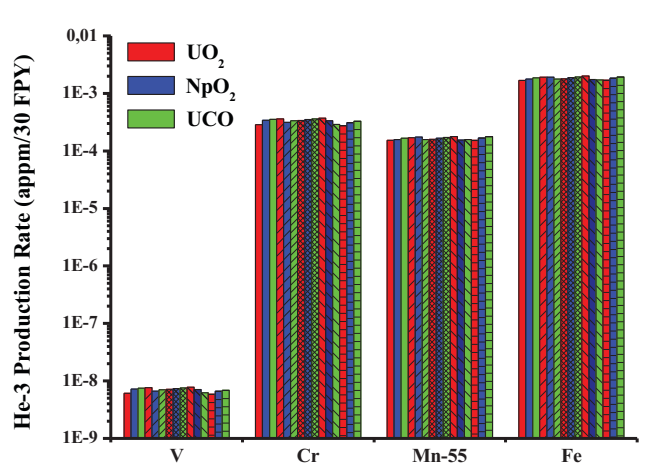

Fig. 4. The contribution of each isotope in the structural material to the total $\mathrm{He}-3$ production rate for the mixture components of $\mathrm{UO}_{2}, \mathrm{NpO}_{2}$ and $\mathrm{UCO}(\square 2 \%, \mathbb{Z Z /} 4 \%$, $6 \%, \mathrm{D} 8 \%$, $10 \%$ in the system.

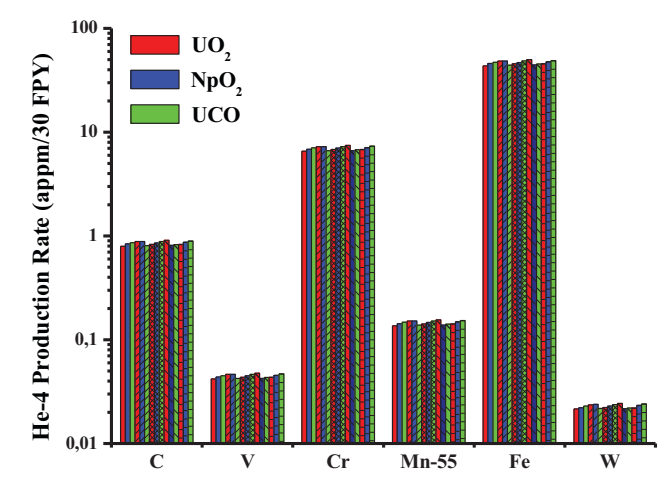

Fig. 5. The contribution of each isotope in the structural material to the total $\mathrm{He}-4$ production rate for the mixture components of $\mathrm{UO}_{2}, \mathrm{NpO}_{2}$ and $\mathrm{UCO} \square 2 \%, \mathbb{Z Z /} 4 \%$, $6 \%, \square \backslash 8 \%$,

Fig. 5 shows comes from $\mathrm{Fe}$ isotope of the biggest contribution and from $\mathrm{W}$ isotope of the smallest contribution at the total $\mathrm{He}-4$ production rate in the structural material for used fluids. In Fig. 5, contribution at the total He- 4 production rate in the structural material of $\mathrm{Fe}$ isotope for used fluids was obtained about 55, $1 \times 10^{3}, 7,3 \times 10^{2}, 2 \times 10^{3}$ times higher than C, V, Cr, Mn55, W isotopes, respectively. In Fig. 5, the contributions to the total $\mathrm{He}-4$ production rate of $\mathrm{Fe}$ isotope in the structural material was found as approximately $85 \%$.

\section{Conclusions}

It this study was observed that the biggest contribution comes from $\mathrm{Cr}$ isotope with approximately $77 \%$ value for the total tritium production rate and from $\mathrm{Fe}$ isotope with approximately $80-99 \%$ between value for the total proton, deuterium, $\mathrm{He}-3$ and $\mathrm{He}-4$ gas production rates in used the structural material. A minimum of gas production is desired, because gas production reduces reactor life and accelerates deterioration of the structural material. In conclusion, the radiation damage parameters obtained according to each isotopes of the structural material in the structural material with $93 \% \mathrm{Li}_{20} \mathrm{Sn}_{80}+$ $5 \% \quad \mathrm{SFG}-\mathrm{PuO}_{2}+2 \% \mathrm{UO}_{2}$ fluid showed the best performance of the fifteen tested fluids.

\section{References}

1. S. Şahin, M. Übeyli, Energy Convers. Manage., 46, 3185 (2005)

2. H. M. Şahin, Ann. of Nucl. Energy, 34, 861 (2007)

3. B. Şarer, et al., Fusion Sci. Technol., 52, 107 (2007)

4. M. Günay, et al., Ann. of Nucl. Energy, 38(12), 2757 (2011)

5. M. Günay, et al., Ann. of Nucl. Energy, 55, 292 (2013)

6. M. Günay, et al., Ann. of Nucl. Energy, 63, 157 (2014)

7. IAEA, International Atomic Energy Agency, IAEATECDOC-1349 (2003)

8. M. Piera, et al., Energy Convers. Manage., 51, 1758, (2010)

9. A.Ying, et al., APEX Interim Report, (1999)

10. B. Şarer, et al., Ann. of Nucl. Energy, 36, 417 (2009)

11. M. Günay, et al., Ann. of Nucl. Energy, 53, 59 (2013)

12. M. B. Chadwick, et al., Nucl. Data Sheets, 107, 2931, (2006)

13. D. B. Pelowitz, MCNPX User's Manual, Version 2.7.0, LA-CP-11-00438 (2011)

14. J. J. Duderstadt, G. A. Moses, New York: John Wiley\&Sons, (1982)

15. J. A. Blink, et al., Lawrence Livermore National Laboratory, UCRL-53559 (1985)

16. M. Perlado, et al., International Atomic Energy, 272, Vienna, (1995)

17. S. Ünalan, Fusion Eng. Des., 38, 393, (1998) 